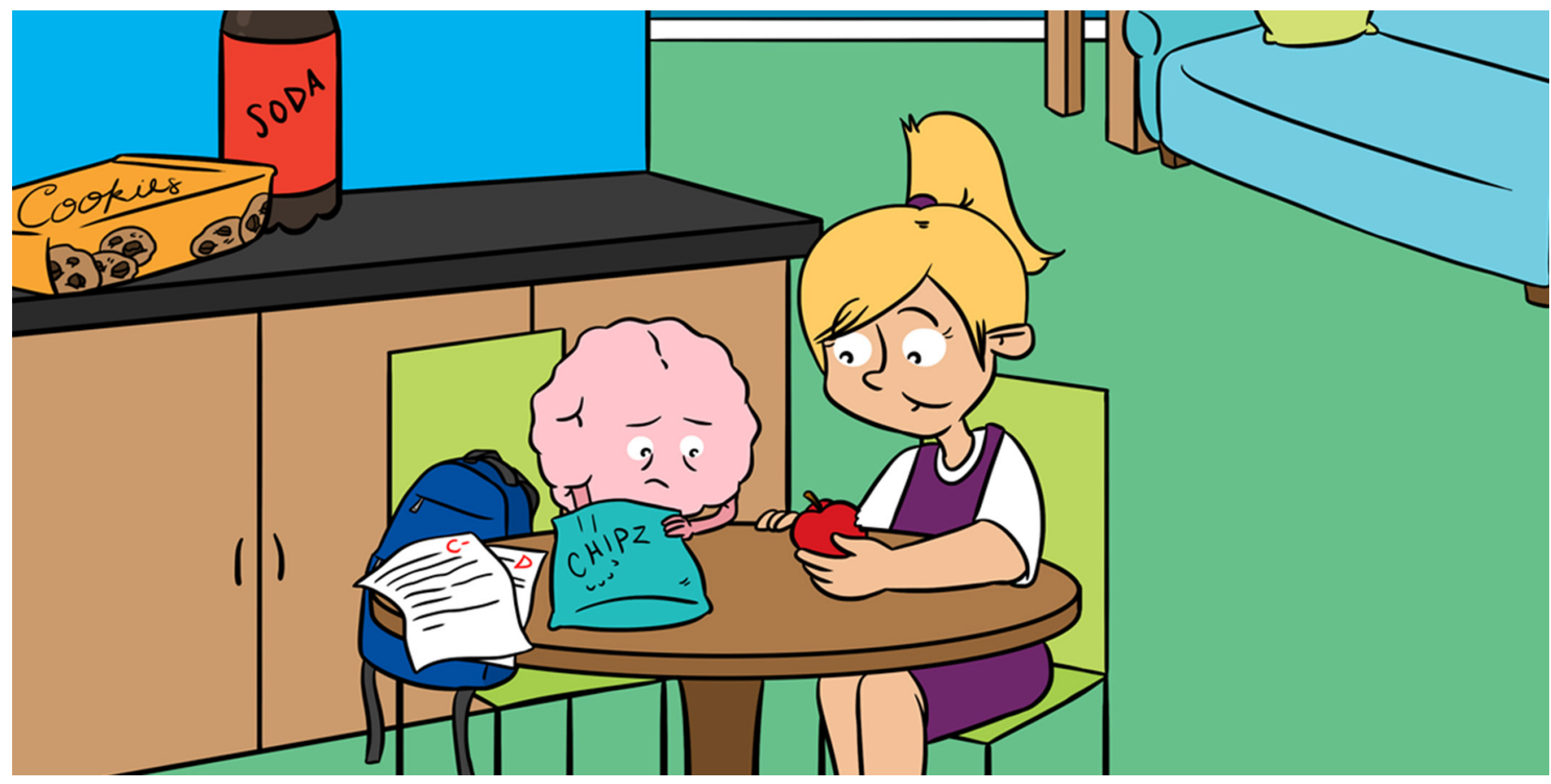

\title{
HEALTHY MEAL, HAPPY BRAIN: HOW DIET AFFECTS BRAIN FUNCTIONING
}

\section{Fatima Ahmad ${ }^{1+}$, Hiba Hasan ${ }^{1 \dagger}$, Samar Abdelhady ${ }^{1,2 *}$, Walaa Fakih ${ }^{3}$, Nawara Osman $^{1}$, Abdullah Shaito ${ }^{4,5^{*}}$ and Firas Kobeissy ${ }^{1 *}$}

${ }^{1}$ Department of Biochemistry and Molecular Genetics, Faculty of Medicine, American University of Beirut, Beirut, Lebanon

${ }^{2}$ Faculty of Medicine, Alexandria University, Alexandria, Egypt

${ }^{3}$ Department of Pharmacology and Toxicology, American University of Beirut, Beirut, Lebanon

${ }^{4}$ Biomedical Research Center, Qatar University, Doha, Qatar

${ }^{5}$ Faculty of Health Sciences, University of Balamand, Beirut, Lebanon

YOUNG REVIEWERS:

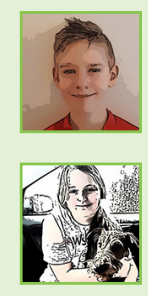

OLIVER

AGE: 15

OLIVIA

AGE: 12
Do you know that the foods you eat impact your health? Most importantly, what you eat can have negative effects on the most complex organ in your body: your brain! Amazingly, the food you eat affects neurons, which are the major cells of the brain. In the brain, an unhealthy diet that is rich in fats and sugars causes inflammation of neurons and inhibits the formation of new neurons. This can affect the way the brain works and contribute to brain disorders like depression. On the other hand, a diet that contains healthy nutrients, such as omega-3 fatty acids, is beneficial for brain health. Such a diet improves the formation of neurons and leads to improved thinking, attention, and memory. In sum, a healthy diet makes the brain happy, so we should all pay attention to what we eat. 


\section{NEURON}

A nerve cell that is the building block of the tissues of the nervous system. A neuron can receive and transmit signals to different parts of the body. A neuron connects with other neurons to transfer their signals. The neuron usually transfers the signals in the form of chemical molecules and electric impulses. A neuron has a cell body (soma), dendrites and an axon.

\section{GLIAL CELLS}

Glial cells are non-neuronal cells of the nervous system. Unlike neurons they do not produce electric impulses. Their functions is to maintain balance in the nervous system by providing support and protection for neurons. Glial cells are of two main types: microglia and astrocytes. Astrocytes can help supply nutrients to neurons while the main function of microglia is to destroy microbes that infect the nervous system.

\section{NEUROGENESIS}

The process by which new neurons are formed in the brain.

\section{SYNAPTIC}

PLASTICITY

The ability of the connections between neurons to become stronger or weaker over time.

\section{FEEDING THE BRAIN}

Like everyone, you may have wondered, "Why do my parents urge me to eat fruits and veggies and to stop eating junk foods?" The answer is, "You are what you eat!" What we eat can determine the composition and the activities of our cells. A healthy diet with the proper amounts of nutrients should be eaten regularly, to keep our cells and organsincluding the brain-healthy.

The brain is the most complex organ of the human body. Throughout life, the brain monitors our daily operations and activities and communicates with other organs, coordinating their functions. Brain cells called neurons communicate with each other and with other organs, such as the muscles. For example, when you want to move your hand, the brain sends a message to muscles in the hand, telling them to contract. Neurons also communicate with other cells in the brain, called glial cells, which support the neurons. There are two types of glial cells: microglia and astrocytes. Microglia are the main immune cells of the brain, helping to protect the brain from infections. Astrocytes provide neurons with the nutrients they need to stay healthy.

You can see that communication-both with other cells in the brain and with the rest of the body-is the brain's most important job. Messages sent by the brain not only allow us to perform physical tasks like moving around, but also help us to perform cognitive tasks. Cognitive tasks include actions like thinking, learning, remembering, memorizing, planning, imagining, organizing, and concentrating. Therefore, a problem that affects the brain can change our thinking, emotions, or behaviors. The proper nutrition found in a healthy diet can improve many brain functions, while a poor diet can have a negative effect on our cognitive functions [1]. A healthy diet is the foundation of a happy brain!

\section{HOW DOES A HEALTHY DIET IMPROVE BRAIN FUNCTIONS?}

There is a direct relationship between the foods we eat and the functioning of our brains. Proper, healthy nutrition can benefit the brain in several positive ways. A healthy diet can increase the production of new neurons, a process called neurogenesis. What we eat can also affect the synaptic plasticity of the brain. Synaptic plasticity is simply a measure of the number of connections between neurons. The more the connections between neurons the better they can communicate, and the better we can learn, think, and memorize.

The hippocampus is one of the most important structures of the brain (Figure 1). It helps to regulate memory and neurogenesis. Neurons, 
Figure 1

The human brain. The hippocampus and the hypothalamus are the brain areas most affected by brain inflammation caused by a diet high in fats. The hippocampus regulates neurogenesis and memory. The hypothalamus, among other functions, is responsible for the control of body weight.

BRAIN-DERIVED NEUROTROPHIC FACTOR (BDNF)

A protein that enhances the growth and survival of neurons.

\section{INFLAMMATION}

It is a protective biological response that starts under harmful conditions, such as stress. It is one way your body fights infection, injury, or disease. It involves immune cells, blood vessels, and many molecules inside the cell.

\section{OMEGA-3 FATTY \\ ACIDS}

They are fats that belong to the chemical class of poly-unsaturated fatty acids. There are three kinds:

docosahexaenoic acid (DHA) and eicosapentaenoic acid (EPA), which are found in certain fish, as well as alpha-linolenic acid (ALA) present in plants like nuts and seeds. They are essential nutrients which means we need to intake them in diet because our body cannot make them. In addition, they were shown to have several health benefits.

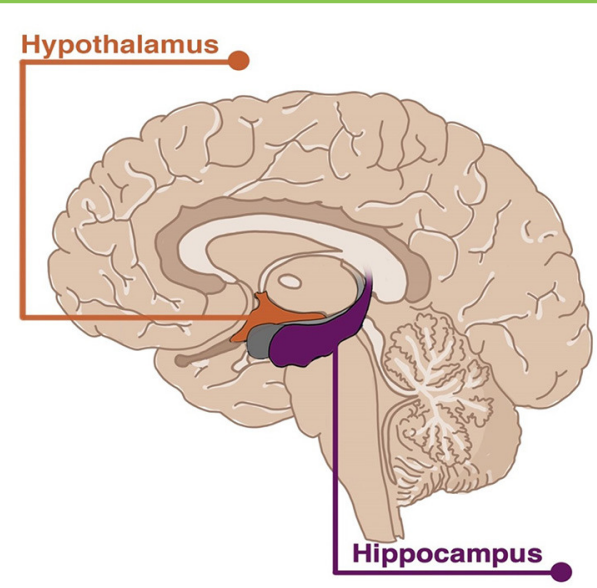

Figure 1

including those in the hippocampus, produce and use many molecules to send and receive messages. Brain-derived neurotrophic factor (BDNF) is one such molecule. BDNF can protect neurons from death, increase neurogenesis, and improve our cognitive abilities. A healthy diet can increase the levels of BDNF and improve neurogenesis in the hippocampus. This increased neurogenesis in the hippocampus can improve our learning, memory, mood, attention, and mental health [2].

\section{WHAT ABOUT AN UNHEALTHY DIET?}

Did you know that the gut and the brain are connected? These two body organs are connected by neurons that transmit messages back and forth between them. The food we eat is sensed by the neurons of the gut, which then send signals to alert the brain. This connection and the resulting communication are called the gut-brain axis. Because of the gut-brain axis, it is not surprising that an unhealthy diet can cause problems with cognitive functions such as remembering, learning, or thinking.

An unhealthy diet causes the body to release too much of a type of stress hormone that can activate the brain's microglia and astrocytes. In fact, the stress hormone activates microglia and astrocytes at times when they should not be active. This activation can cause inflammation in certain parts of the brain, including the hippocampus. Inflammation in the hippocampus can negatively affect our cognitive abilities, which makes it harder to plan, focus, or remember things. This inflammation can even lead to depression [3].

\section{WHAT SHOULD I EAT TO KEEP MY BRAIN HEALTHY?}

Certain food we eat can help our brains to function properly. Food components such as omega-3 fatty acids have been shown 
to improve brain function [3]. If we do not eat enough omega-3 fatty acids, then inflammation-and its resulting negative cognitive effects-may take place in the brain. Omega- 3 fatty acids are an essential nutrient, which means that we need to get them through what we eat because the body cannot make them. One omega-3 fatty acid, called $\alpha$-linolenic acid, is common in plants like walnuts and in edible seeds like flax seeds. Eicosapentaenoic acid and docosahexaenoic acid (DHA) are found in fish oils. A diet rich in fish oil and omega-3 fatty acids can decrease the risk of certain brain disorders, such as Alzheimer's disease or depression.

In our lab, we asked whether DHA could protect the neurons of mice after a brain injury. We and other scientists found that DHA can lower the amount of inflammation that happens in the brain following brain injury. We also found that DHA increases neurogenesis and decreases the death of neurons that are injured. Finally, DHA increases the numbers of microglia and astrocytes near the location of brain injury. Interestingly, when DHA helped to decrease the death of neurons, the injured mice showed better cognitive abilities than mice that were injured but did not receive DHA.

Studies by other scientists have indicated that taking DHA during pregnancy can improve the development of the neurons of the unborn baby $[4,5]$. Also, DHA is needed in early life when the body and brain are still growing. In fact, intake of DHA at young age can increase the formation of new neurons (neurogenesis) and improve cognitive abilities. On the other hand, if young people do not get enough DHA there can be negative effects, since their brains are still developing and that is when DHA is most important. Scientists have found that young people who do not get enough DHA can have problems with neurogenesis, which can lead to issues with behavior and cognition. Interestingly, intake of DHA can reverse these negative effects. From all this evidence, you can probably see that getting lots of omega-3 fatty acids in your diet will help keep your brain healthy!

Mental processes that include thinking, reasoning, remembering, and imagining.

\section{WHICH FOODS SHOULD I AVOID TO KEEP MY BRAIN HAPPY?}

When it comes to brain health, knowing which foods to avoid is just as important as knowing which foods to eat! A bad diet can be unhealthy for your body and your brain. For example, eating a lot of sugars can affect the brain's memory and learning functions. Sodas contain a lot of sugars, and even diet sodas, which contain artificial sweeteners, are not good for the brain. The artificial sweetener, aspartame, in diet sodas can make you irritable or anxious and can cause sleep disturbances (Figure 2). 
Figure 2

Effects of unhealthy foods on the brain. Drinking sodas or energy drinks containing the artificial sweetener aspartame can cause irritability, anxiety, and sleep difficulties called insomnia. Eating trans-fats can increase the risk of cognitive problems and Alzheimer's disease. Too much sugar in the diet can affect brain's memory and learning abilities.

\section{OXIDATIVE STRESS}

Cellular stress that leads to damage of molecules inside cells, such as lipids, proteins, and DNA.

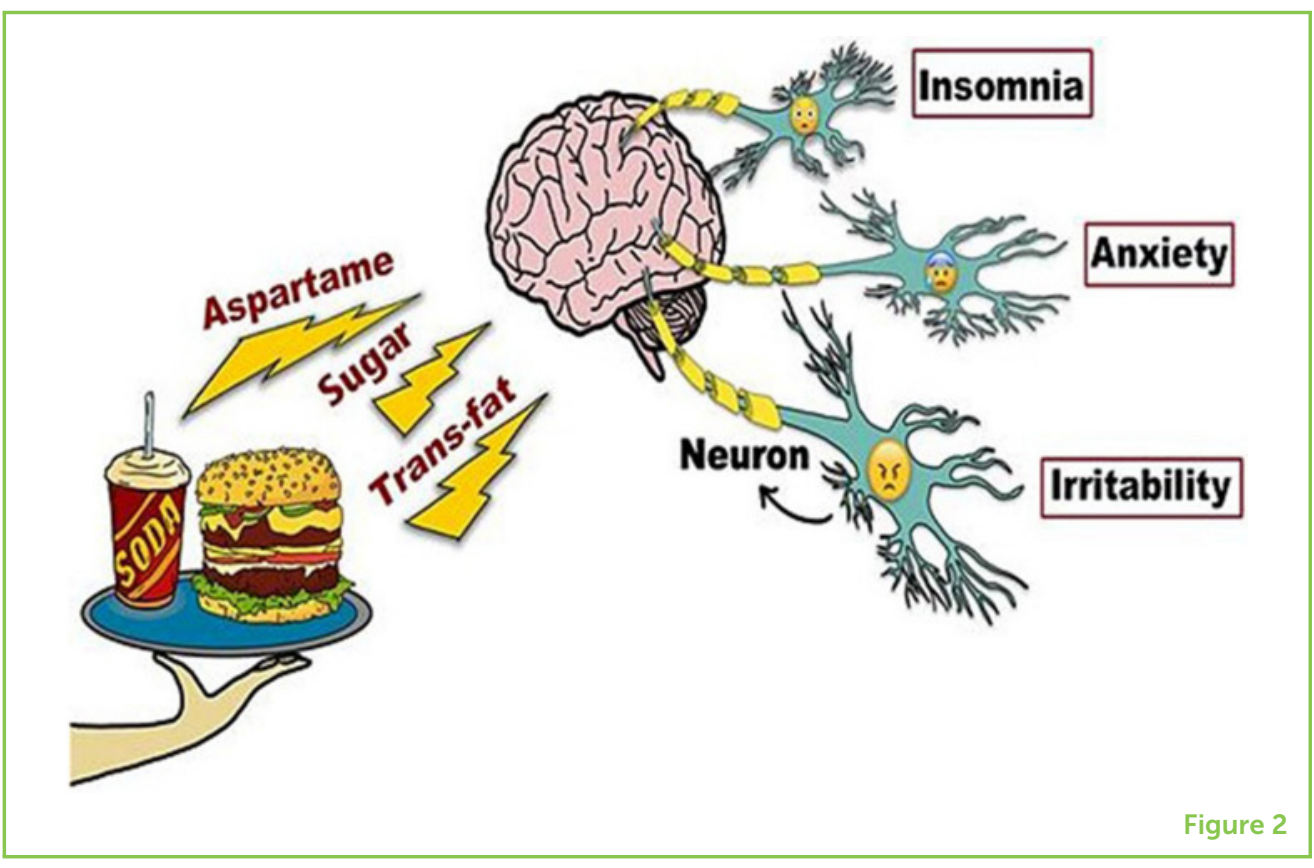

A high-fat diet is also unhealthy because it can lead to oxidative stress in the brain. Oxidative stress is a harmful process that can disrupt several structures inside cells [6]. In addition, scientists have found that consuming a high-fat diet can activate microglia, which can cause inflammation in both the hippocampus and the hypothalamus, which are important areas of the brain (Figure 1). The hypothalamus is responsible for control of body weight, among other functions. Inflammation in the brain's weight-control center can make a person eat even more [7].

Have you heard of trans-fats? Trans-fats are artificial fats that are considered the worst type of fats to eat. Trans-fats have many negative effects, but in the brain, they can increase the risk of cognitive problems, anxiety, and even Alzheimer's disease. Trans-fats can be found in margarines, frostings, snacks, and store-bought cookies and cakes. So, avoid them to protect your brain!

In another experiment in our lab, we fed a group of mice a high-fat diet for a long period of time. These mice gained a lot of weight and became obese! These obese mice, due to eating a high-fat diet, had much more inflammation in their brains and more death of neurons in response to brain injury than did thin mice eating a normal diet. Other scientists found that eating a high-fat diet can even delay the recovery of a person suffering from a brain injury, by decreasing production of BDNF in the brain, leading to a decrease in neurogenesis [8]. Decreased neurogenesis makes it harder for the brain to regain its functions after an injury. As if this is not bad enough, a high-fat diet can worsen memory, learning, and other cognitive problems that take place after a brain injury. 


\section{Figure 3}

Eating healthy foods, and avoiding unhealthy foods, can help to keep the brain healthy. In general, healthy foods contain proper amount of carbohydrates, proteins, calcium, vitamins, minerals, and fibers, however, unhealthy foods contain high amount of sugars and fats.

\begin{tabular}{|c|c|c|}
\hline \multicolumn{2}{|r|}{ Healthy Foods } & Unhealthy Foods \\
\hline Carbohydrates: & $\begin{array}{l}\text { Bread } \\
\text { Rice } \\
\text { Noodles }\end{array}$ & Smoked meat and barbequed meat \\
\hline Proteins: & $\begin{array}{r}\text { Fish } \\
\text { Meat } \\
\text { Beans }\end{array}$ & $\begin{array}{l}\text { Sugary drinks (soda) } \\
\text { Fried foods (potato chips and }\end{array}$ \\
\hline Calcium: & $\begin{array}{c}\text { Eggs } \\
\text { Milk } \\
\begin{array}{c}\text { Dairy products: yogurt, cheese, and } \\
\text { butter }\end{array}\end{array}$ & $\begin{array}{c}\text { French fries) } \\
\text { Sugary dairy products (ice cream) } \\
\text { Foods containing high salts and } \\
\text { high fats }\end{array}$ \\
\hline $\begin{array}{l}\text { Vitamins, Minerals, } \\
\text { and Fibers: }\end{array}$ & $\begin{array}{c}\text { Vegetables } \\
\text { Fruits and fruit juices } \\
\text { Beans }\end{array}$ & $\begin{array}{l}\text { Cookies and chocolates } \\
\text { White flour } \\
\text { Candy }\end{array}$ \\
\hline
\end{tabular}

\section{TAKE-HOME MESSAGE}

The brain performs many essential functions, including regulating our mental health and physical well-being. So, we should work hard to keep it healthy! As a result, we should be careful when choosing what we eat, since our diet can have a huge impact on brain health. We should eat foods rich in healthy nutrients, such as omega-3 fatty acids. A healthy diet can improve our cognitive functions, such as our ability to concentrate, remember, learn, and think. We should also try to avoid or minimize the intake of foods rich in fats or sugars, which when taken in high amounts can lead to inflammation in the brain, decreased neurogenesis, and defects in brain functions. Figure 3 can help guide you in your diet decisions. A healthy diet will help your brain perform better, and this will help you to learn better at school, remember things more easily, and avoid quick changes in mood. To conclude, carefully watch what you eat, since your diet can make or break it when it comes to your brain health!

\section{REFERENCES}

1. Ackerman, S. 1992. Discovering the Brain. Washington, DC: National Academies Press.

2. Zainuddin, M. S., and Thuret, S. 2012. Nutrition, adult hippocampal neurogenesis and mental health. Br. Med. Bull. 103:89-114. doi: 10.1093/bmb/lds021

3. Spencer, S. J., Korosi, A., Layé, S., Shukitt-Hale, B., and Barrientos, R. M. 2017. Food for thought: how nutrition impacts cognition and emotion. NPJ Sci. Food 1:7. doi: 10.1038/s41538-017-0008-y 
4. Ghazale, H., Ramadan, N., Mantash, S., Zibara, K., El-Sitt, S., Darwish, H., et al. 2018. Docosahexaenoic acid (DHA) enhances the therapeutic potential of neonatal neural stem cell transplantation post-traumatic brain injury. Behav. Brain Res. 340:1-13. doi: 10.1016/j.bbr.2017.11.007

5. Lauritzen, L., Brambilla, P., Mazzocchi, A., Harsløf, L. B., Ciappolino, V., Agostoni, C. 2016. DHA effects in brain development and function. Nutrients 8:6. doi: 10.3390/nu8010006

6. Tan, B. L., and Norhaizan, M. E. 2019. Effect of high-fat diets on oxidative stress, cellular inflammatory response and cognitive function. Nutrients 11:2579. doi: $10.3390 /$ nu11112579

7. Reichelt, A. C., Westbrook, R. F., and Morris, M. J. 2017. Editorial: impact of diet on learning, memory and cognition. Front. Behav. Neurosci. 11:96. doi: 10.3389/fnbeh.2017.00096

8. Wu, A., Molteni, R., Ying, Z., and Gomez-Pinilla, F. 2003. A saturated fat diet aggravates the outcome of traumatic brain injury on hippocampal plasticity and cognitive function by reducing BDNF. Neuroscience 119:365-75. doi: 10.1016/S0306-4522(03)00154-4

SUBMITTED: 30 June 2020; ACCEPTED: 02 July 2021; PUBLISHED ONLINE: 03 August 2021.

EDITED BY: Bahtiyar Yilmaz, Bern University Hospital, Switzerland

CITATION: Ahmad F, Hasan H, Abdelhady S, Fakih W, Osman N, Shaito A and Kobeissy F (2021) Healthy Meal, Happy Brain: How Diet Affects Brain Functioning. Front. Young Minds 9:578214. doi: 10.3389/frym.2021.578214

CONFLICT OF INTEREST: The authors declare that the research was conducted in the absence of any commercial or financial relationships that could be construed as a potential conflict of interest.

COPYRIGHT @ 2021 Ahmad, Hasan, Abdelhady, Fakih, Osman, Shaito and Kobeissy. This is an open-access article distributed under the terms of the Creative Commons Attribution License (CC BY). The use, distribution or reproduction in other forums is permitted, provided the original author(s) and the copyright owner(s) are credited and that the original publication in this journal is cited, in accordance with accepted academic practice. No use, distribution or reproduction is permitted which does not comply with these terms.
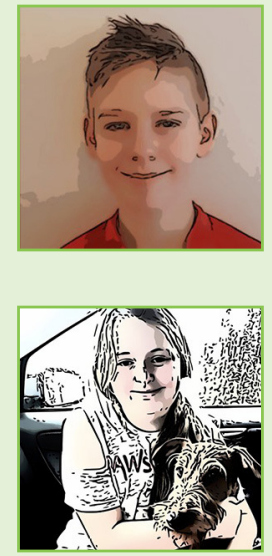

\section{YOUNG REVIEWERS}

\section{OLIVER, AGE: 15}

I am Oliver, a 15 (soon 16) year old boy from Norway. I enjoy ball games, either volleyball, soccer, or badminton, and I love working on my motor cycle. I do not have much experience in science, but I find it interesting to read "easily explained" science.

\section{OLIVIA, AGE: 12}

My name is Olivia. I am 11 years old. I joined Frontiers for Young Minds because I like 

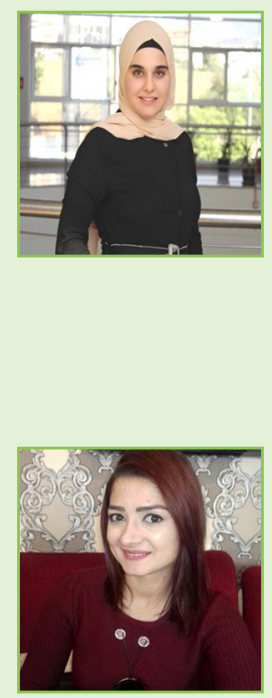

science, reading, and doing experiments. I like animals, especially dogs. I have an Irish Terrier. My hobbies are playing piano, singing, and karate. I like to travel.

\section{AUTHORS}

\section{FATIMA AHMAD}

I am a neuropsychologist and a researcher who loves to study the interaction between our brains and the environment. My research, at the American University of Beirut, focuses on understanding the effects of lifestyle factors, including high fat diet, on the pathogenesis of traumatic brain injuries. I like to discuss and communicate science, since sharing knowledge is necessary to reveal the mysteries of the brain. I believe that persistence, dedication, hard work, kindness, and optimism are the key ingredients for success.

\section{HIBA HASAN}

I am currently a volunteer in the Biochemistry and Molecular Genetics Department at the American University of Beirut. The lab focuses on understanding brain injuries and tests cell- and drug-based therapies for traumatic brain injuries. I have a master's degree in biology with a specialization in immunology, during which I tested the anti-inflammatory and antioxidant activities of natural agents on autoimmune diseases. I hope to pursue a Ph.D. focusing on the cause of autoimmune disorders and hope to find a cure for such diseases.

\section{SAMAR ABDELHADY}

I am a medical doctor. I did a research internship in Dr. Kobeissy's lab at the American University of Beirut to study traumatic brain injury using animal models. In my free time, I love drawing scientific illustrations and brain art, watching movies that talk about the brain, and, since I work for long hours at a desk, I enjoy going hiking to keep my body fit. *samar.abdelhady606@gmail.com

\section{WALAA FAKIH}

Walaa Fakih is a master's graduate from Lebanese University, Faculty of Science. She joined Dr. Firas Kobeissy's lab where she worked on therapies for neural cells. Later, she joined the lab of Dr. Ahmed El Yazbi in the Department of Pharmacology and Toxicology, where her research focused on the effects of increased caloric intake on problems of cognition. Recently, she was accepted for a Ph.D. position at University of Strasbourg. She aims to find protective therapies to prevent heart and nerve problems associated with obesity and diabetes.

\section{NAWARA OSMAN}

I am a Lebanese research student pursuing a M.Sc. in biochemistry at the American University of Beirut (AUB). I am doing my thesis project in Dr. Kobeissy's lab, where I am focusing on the behavioral, molecular aspects of repeated concussions. I earned a bachelor's degree in biochemistry from the Lebanese International University. I aim to pursue a doctoral degree and be a part of further achievements in science. 


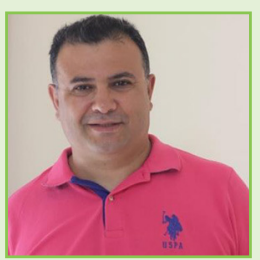

\section{ABDULLAH SHAITO}

I obtained my Ph.D. at the University of Texas Southwestern at Dallas (USA), where I studied bacterial interaction with intestinal cells. Currently, I am an Assistant Professor at Lebanese International University (Beirut, Lebanon). My current research projects include the pathogenesis of traumatic brain injury and its therapy using different kinds of stem cells, and the cell-cell communication that happens in different cancers. I also teach several core biology courses to undergraduates. Email me when you get into college and need help in your biology courses. *abdshaito@gmail.com

\section{FIRAS KOBEISSY}

I am a neuroscientist with extensive experience in experimental brain injury. I am an Assistant Professor at the Department of Biochemistry at the American University of Beirut. I obtained my Ph.D. in neuroscience from the University of Florida. My current research focuses on identifying proteins that mark the incidence of traumatic brain injury using a technique called neuroproteomics. I am a member of the Center of Neuroproteomics and Biomarker Research and the Center for Traumatic Brain Injury Studies at the McKnight Brain Institute at the University of Florida. *firasko@gmail.com

${ }^{\dagger}$ These authors have contributed equally to this work and share first authorship 